\title{
Relatos ficcionales: entre el retrato y el simulacro
}

\section{LAURA RIBERO RUEDA}

Laura Ribero Rueda é artista plástica e pesquisadora, Doutora em Artes Visuais pela Universidade de Barcelona, Espanha (2013). Atua na área de fotografia produzindo trabalhos artísticos ligados às questões de espacialidade e migração. Atualmente é professora no curso de Fotografia e Artes Visuais, e coordenadora do Espaço Cultural da Universidade Feevale, Novo Hamburgo, RS. 


\section{- RESUMEN}

El objetivo de éste artículo es reflexionar acerca del retrato fotográfico como una construcción de imaginarios, en la que se asume la identidad como una multiplicidad y en donde el concepto de realidad se diluye en el territorio de lo ficcional. La pose y la simulación hacen parte del retrato fotográfico, en el que el yo se reconoce como una pluralidad, una entidad dinámica en la que permanentemente cuestionamos acerca de lo que es real y acerca de quien es ese yo -o ese otro- que quiero presentar fotográficamente.

\section{- PALABRAS CLAVE}

Retrato, fotografía, simulacro, identidad, otredad

\section{- RESUMO}

O objetivo deste artigo é refletir acerca do retrato fotográfico como uma construção de imaginários, assumindo a identidade como uma multiplicidade, onde o conceito de realidade esta diluído no território da ficção. A pose e a simulação são parte do retrato fotográfico, onde o eu é reconhecido como uma pluralidade, uma entidade dinâmica onde permanentemente questionamos acerca de que é real e acerca de quem é esse eu -ou esse outro- que desejo apresentar fotograficamente.

\section{- PALAVRAS-CHAVE}

Retrato, fotografia, simulacro, identidade, alteridade

\section{- ABSTRACT}

The aim of this article is a reflection about photographic portrait as a construction of imaginaries, assuming the identity as a multiplicity, where the concept of reality is blended in fictional territory. The pose and simulation are part of photographic portraiture; the self is recognized as a plurality and a dynamic construction that constantly questioned about who is real and about who is the self -or the otherness -that I want to show on the photograph.

\section{- KEYWORDS}

Portrait, photography, simulation, identity, otherness

\section{Introdução}

Dentro de la Historia del Arte y de la Fotografía, el retrato ha sido utilizado como vehículo que transmite pluralidades y a su vez, singularidades de identidades que no necesariamente reflejan el propio yo. Desde finales de los años 70 , junto con el arte conceptual, surgen artistas como Cindy Sherman y Yasumasa Morimura, que son nombres determinantes dentro de la fotografía porque con su obra cuestionan la construcción simbólica y estética del yo, ubicándose en el cruzamiento entre la simulación, la memoria y la construcción colectiva y personal. Artistas que asumen la pluralidad del yo, creando conscientemente un trabajo fotográfico que se basa en la multiplicidad del retrato y de la identidad. 
Un yo que se construye y deconstruye frente a la lente fotográfica, existiendo tan solo en ese único momento. Un performance que se desenvuelve frente a la cámara, creando una acción efímera pensada especialmente para ser registrada y que acentua la idea de fotografia escenificada, de construcción de la imagen fotografíca, y por ende de la construcción de conceptos relativos a esa imagen: trascendiendo la imagen espontánea asociada comunemente a la fotográfia, para desvelar los mecanismos de elaboración visual intrínsecos a la propia imagen.

Este artículo, es una reflexión teórica acerca de la construcción del sujeto, en cuanto imagen fotográfica. Pretendemos establecer la dimensión teórica que subyace a la construcción del retrato fotográfico, asumiendo la puesta en escena y la pose delante de la cámara fotográfica, como elementos caracteristicos del retrato y que evidencian un yo que siempre está en entredicho: que no se asume como una unidad, sino que se construye a partir de la multiplicidad.

La metodología de investigación empleada es predominantemente cualitativa, por medio del análisis y crítica de textos relacionados con la estética e interpretación de la imagen y con conceptos relativos a la identidad y la otredad. La base de esta investigación es el análisis de fotografias de artistas contemporáneos, de los cuales mencionamos algunas referencias, y que colaboran con el propósito de construir un panorama que incluya una perspectiva filosófica y sociológica alrededor del concepto del yo y sus implicaciones en el retrato fotográfico.

\section{El yo, los otros}

\subsection{El retrato fotográfico: el yo en relación al otro}

Aunque existen variantes del retrato fotográfico -tales como el psicológico, el de moda, el médico, el antropológico- hay una pretensión última de captar fielmente al individuo. Es en el retrato antropológico y psicológico donde se acentúa la intención de revelar el yo más interno del sujeto fotografiado. Sin embargo, 'la afirmación de la permanencia y la estabilidad del yo se han tambaleado junto con la postmodernidad. Jacques Lacan (citado por RUBIO, O., 2004, p.17) afirma que el yo es una construcción imaginaria.'

El retrato fotográfico es una acción conjunta, en la que el fotógrafo interviene para materializar la identidad del individuo. Sin embargo no lo hace como simple 
espectador, sino que invariablemente aporta su subjetividad en el momento de disparar el obturador. Es decir que el yo, está mediado por la percepción del fotógrafo, y a su vez por el contexto y el momento en que se realiza la fotografía, revelando la naturaleza mutable del sujeto.

Más explicitamente, podríamos definir diversas variables que entran en juego a la hora de registrar fotogáficamente al sujeto: por una parte está la imagen que el sujeto tiene de sí mismo, determinada por el momento específico de la toma de la fotografía -aunque no de la totalidad de su identidad, que sería inabarcable en el negativo-. Por otra parte, habría que tener en cuenta que un mismo sujeto está compuesto por múltiples yoes, que lo hacen indefinible; y que a su vez interactua con el yo del fotógrafo y del espectador, quienes construyen otra mirada acerca de un mismo yo, dando como resultado una relación imaginaria y parcial. (CASTILLA DEL PINO, 2000)

De la misma manera Barthes (1999) sintetiza los cuatro imaginarios que se cruzan frente al objetivo fotográfico, afrontándose o deformándose: aquel que creo ser, aquel que quisiera que crean que soy, aquel que el fotógrafo cree que soy y aquel de quien se sirve para exhibir su arte. La fotografía, según el autor, es una empalizada de fuerzas, en la que las percepciones subjetivas acerca del yo determinan la vulnerabilidad de la identidad del sujeto fotografiado. Tal como lo afirma Kertész (2010, p.13): 'Yo: una ficción de la que a lo sumo somos coautores.'

En última instancia, el yo fotografiado es una fragmentación de la totalidad del sujeto. El yo, en el retrato fotográfico es una construcción que se elabora en el momento del registro químico o digital, y que se sigue transformando por la subjetividad de quienes observan el retrato. Es decir, que es una entidad dinámica, en la que el yo, siempre es visto como otro; no como una totalidad independiente, sino como una parte que entra a definirse en relación con otros yo. Barthes (1999) afirma: el yo es el advenimiento como otro, es una disociación de la identidad.

Por eso la búsqueda de uno mismo entre los demás, incluso entre los que habitaron el sujeto, es una búsqueda desplegada siempre en la ficción: el sujeto implique lo que implique ese concepto- anda siempre escapándose. Probablemente es esa brecha, la conciencia de esa fractura profunda, de esas omisiones y de esa impunidad que busca el sujeto contemporáneo (...) (DE DIEGO, 2011, p. 47-48) 
El reto de asumirse como otro en el retrato fotográfico, es deliberadamente una opción del sujeto o del fotógrafo; y no necesariamente implica la anulación de la propia identidad. En el ejercicio de fotografiar, la pose y la simulación hacen parte del retrato y pueden ayudar a construir un nuevo imaginario identitario que también identifica al sujeto.

(...) un retrato del otro puede terminar siendo un autorretrato del propio artista, abundan las obras en las que el autor se fotografía a sí mismo asumiendo el papel del otro, sea éste un ancestro, un estereotipo mostrado por los medios de comunicación o un rol culturalmente asimilado por su género o su raza. (PARDO SAINZ, 2011, p. 255)

La asimilación del retrato fotográfico es en última instancia, una identificación por parte del espectador, el cual reconoce, siente afinidad o curiosidad por el sujeto retratado. El otro no existe por sí mismo, sino que se construye en relación con base en nuestro imaginario, el cual es un reflejo del imaginario implantado en la sociedad a la cual pertenecemos; y esa definición o identificación con otro individuo, depende de la herencia cultural y visual en donde podemos registrar mentalmente a dicho sujeto.

'Percibir al otro puede depender de un proceso de incorporación de esa persona, de que consigamos que el otro sea una prolongación de uno mismo.' (BROWN, 2004, p.17) A raíz de las múltiples interpretaciones que tenemos del otro, siempre queda algún vestigio en esas representaciones que se refieren a uno mismo, de cómo uno ve al otro.

\subsection{La multiplicidad del sujeto}

En las teorías posmodernas y poscolonialistas hay una referencia clara a la fragmentación y la pluralidad del sujeto: '(...) reconocer en el marco de lo políticamente correcto la existencia del otro múltiple, su capacidad transgresora y su alteridad.' (GUASCH, 2005, p.7)

Sin embargo, tal reconocimiento también se aplica al propio yo. Ya lo afirmaba Arthur Rimbaud (1871): 'Je est un autre' ${ }^{1}$, que nos lleva a la verificación que

\footnotetext{
${ }^{1}$ Traducción nuestra: 'Yo es otro.' Esta afirmación se encuentra en 'Lettres du Voyant' (traducción nuestra: 'Cartas del Vidente'), escrito el 13 de mayo de 1871 por el poeta francés Arthur Rimbaud para su antiguo profesor Georges Izambard.
} 
nosotros mismos somos algo extraño, que podemos devenir otro: 'A menudo cuando uno intenta decir quién es, descubre que para representar su identidad tiene que inventarla y decir que es otro. Fernando Pessoa (citado por BROWN, 2004, p.17), con sus heterónimos, va más allá para decir 'yo es otros', el yo es una pluralidad.'

Ani Bustamante (2010) propone justamente esa pluralidad a partir de la obra de Pessoa: 'yo es otros', quien parte de la multiplicidad de identidades para trascender el enunciado de Rimbaud, y reconocer que nuestro inconsciente está habitado por múltiples vicisitudes del sujeto -que aún cuando no todas son evidentes para el mismo sujeto-, sí que conforman las claves de nuestra propio universo. Pessoa conlleva en sí mismo, este simbolismo del desbordamiento ficticio, de asumir plenamente un personaje mientras el yo desaparece entre capas de sentido, y da paso a esas múltiples voces que lleva dentro de sí, pero que no se pueden reducir a un simple yo o un simple otro.

'No existe el Otro, sino multitud de otros', afirma Trouillot (2003, p.27); en concordancia con Pessoa y a pesar de las narrativas totalizadoras es infinitamente inabarcable, y siempre dependiente de las circunstancias y el contexto en el que se encuentra.

Efectivamente, el YO unitario moderno ha sido dinamitado y sobre sus cenizas se reconstruye un nuevo ser plurifacético y consciente de su propio simulacro existencial, que bucea en su representación y en la realidad que se oculta tras esa imagen. Para que esto sea posible es necesaria la aparición del arte narrativo que combina la imagen con la palabra, la representación con el testimonio de la realidad, y el lenguaje icónico con el verbal. (PARDO SAINZ, 2011, p.311)

\subsection{Autorretrato y autorreferencialidad}

En la creación contemporánea, existen diferentes aproximaciones al sujeto: por una parte está la referencia a la otredad, y por otra, hay una propuesta autorreferencial, en donde los mismos autores, a través de su trabajo artístico, se relacionan con los otros como una alteridad.

Existe una intencionalidad de varios artistas contemporáneos que retratan fotográficamente -ya sea con su propio cuerpo o el de otros- la individualidad, como reflejo de una colectividad.

El reflejo precisamente, es para Jorge Luis Borges (1997, p. 86) una metáfora para la autorreferencialidad: 
Existen dos estéticas: la estética pasiva de los espejos y la estética activa de los prismas. Guiado por la primera, el arte se transforma en una copia de la objetividad del medio ambiente o de la historia psíquica del individuo. Guiado por la segunda, el arte se redime, hace del mundo un instrumento, y forja su visión personal.

En el arte contemporáneo hay referencias reiteradas hacia la propia individualidad, en términos de identidad, género y cuerpo. Según Marta Gili (1998), quien reflexiona a partir de la lectura de Borges, hay muchas propuestas artísticas que tratan el reflejo que el espejo devuelve al sujeto, en un intento por reducir y domesticar una realidad cada vez más cambiante, inaccesible y caótica.

Sin embargo, es la refracción de los prismas la que posibilita, según Borges, la interacción en otros campos diferentes al propio reflejo; áreas que trasgreden nuestra cotidianidad inmediata para instalarse en otros tiempos históricos o en otros contextos culturales. Las revisiones históricas y los trabajos que remiten a la memoria, permiten hallar múltiples lecturas de un mismo acontecimiento, que es visto a través de ese prisma del cual se vale el artista para relacionar su cotidianidad con otras esferas de conocimiento y con otros sujetos (GILI, M. [curadora] et al, 1998), convirtiendo la identidad y la memoria en temas recurrentes en el arte autorreferencial.

Artistas como Nabil Boutros, Samuel Fosso o Guillermo Gomez-Peña, expresan en sus autorretratos fotográficos diferentes representaciones de colectividad, utilizando su propio cuerpo como vehículo de manifestación de diversas identidades. Podemos detenernos por un momento en la obra del artista egipcio Nabil Boutros $^{2}$, quien realizó en 2010 una de sus obras con más repercusión política: 'Egyptians'. (Figura 1) Boutros es el único protagonista de 25 autorretratos que corresponden a las letras del abecedario internacional y en los que en cada uno de ellos, muestra una manera diferente, y al mismo tiempo, singular, de ser egipcio.

Boutros se instala desde la ambigüedad que supone modificar algunos detalles físicos además de su vestimenta, lo que significa, que en cada retrato se apropia de una nueva identidad. En la sociedad egipcia, tal cambio en la apariencia acarrea una identificación religiosa y política contundente. Mediante ésta obra,

\footnotetext{
${ }^{2}$ Boutros nació en El Cairo, Egipto en 1954. Estudió Artes Decorativas en su ciudad natal y Bellas Artes en Paris, Francia, donde vive y trabaja actualmente.
} 
Boutros (2011) cuestiona la permanencia de la identidad: '(...) todas las personas tienen múltiples caras, pero al final el hábito hace al monje'. (traducción nuestra) ${ }^{3}$.

La apariencia y la ropa son las que definen, en primera instancia, la identidad de una persona y mediante la cual se puede juzgar a simple vista sus intereses, o al menos los intereses visibles que trasmite por medio del lenguaje corporal. Boutros trasgrede su propia imagen para tratar los estereotipos que están relacionados con su género y su cultura. Sin embargo, su obra se enmarca en un contexto histórico específico, que lo dota de un acentuado carácter político.

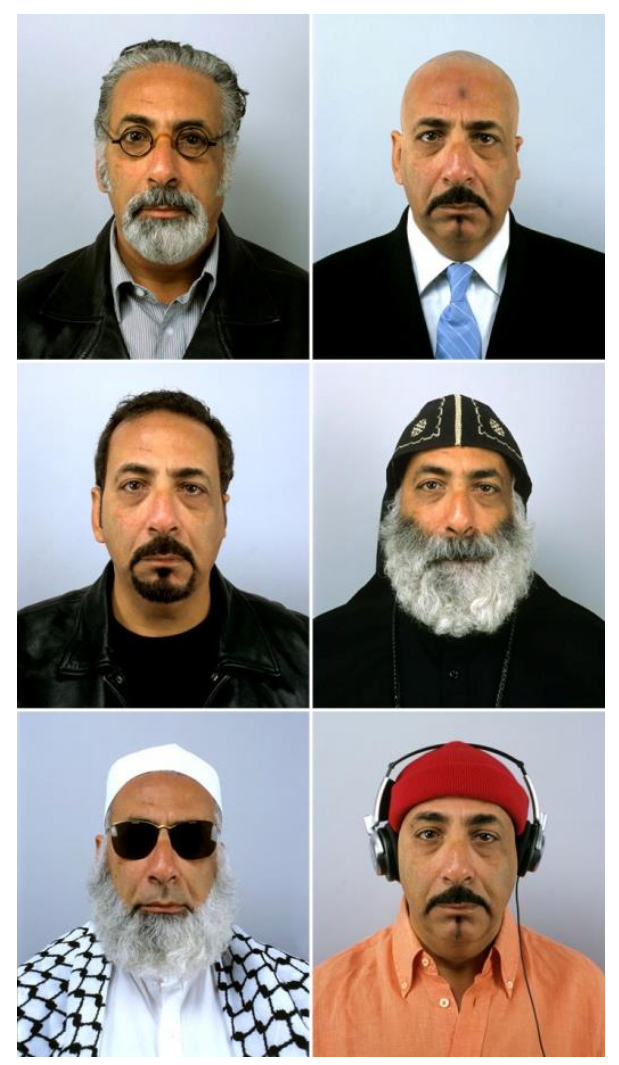

Figura 1 - Nabil Boutros, de la serie Egyptians (de izquierda a derecha y de arriba abajo: Egyptian A, Egyptian B, Egyptian G, Egyptian M, Egyptian R, Egyptian), c-print, 2010. Fuente: Página web del artista. ${ }^{4}$

Boutros acoge en un mismo trabajo, muchos de los estereotipos que definen al egipcio contemporáneo, aunque en si mismo destruye la noción de paradigma: estereotipos son todos o quizás ninguno, ¿cuál es el que nos habla del verdadero yo?

\footnotetext{
${ }^{3}$ En el original: '(...) everyone has multiple faces; at the worst, that clothes make the man.' (Boutros, 2011)

${ }^{4}$ Para más información, dirigirse a: www.nabil-boutros.com/
} 
La realidad de cada persona, de cada singularidad, indudablemente va más allá de su vestimenta, etnia o clase social.

Como se puede entrever, se trata de un juego artificioso de ventanas y espejos en el que lo real ha quedado disuelto en su apariencia.' (GONZALO PRIETO, 2003, p.27) La dinámica de los contextos y de la identidad, hace que la autorreferencialidad -y por consiguiente el autorretrato- sea una entidad móvil, la cual, como apunta Baudrillard (2008), va más allá del simple reflejo para generar modelos sin un origen o una realidad.

La percepción de mi propio yo entra en un juego en el que se entrelazan apariencia y realidad, y acorde a la teoría de Baudrillard, se convierte en un simulacro constante, definido por un conjunto de espejos socialmente construidos, en el que la realidad desaparece y se sustituye por un mundo de imágenes e de ilusiones, integrado en la cultura de masas. (BRAVO, 2006; REBOLLAR, 2003)

En última instancia, el retrato es el espacio donde entran en conflicto la identidad y la apariencia. 'En un mundo donde la imagen y la superficie son parte esencial de nuestra identidad, el retrato se manifiesta en uno de los máximos exponentes del arte contemporáneo.' (GONZALO PRIETO, 2003, p.93-94) Y es precisamente el retrato fotográfico el que ha generado una conciencia sobre la propia imagen, y a su vez, una conciencia acerca de la simulación de la identidad, de la separación entre el cuerpo y el yo, entre el cuerpo y la imagen.

\section{Entre la realidad y el simulacro}

\subsection{Los relatos ficcionales}

La posmodernidad trajo consigo la certeza de que no existe una historia unitaria ni real. La veracidad del documento fotográfico, al que se le ha encargado de preservar un testimonio visual de esa historia, pareciera estar en continua relación con los simulacros de realidades, y no con la realidad en sí misma.

Las nuevas estrategias de representación reivindican los relatos ficticios como dignos de ser legitimados por la imagen fotográfica a la vez que sirven para llamar la atención sobre la relatividad de lo verosímil. Ponen sobre el tapete la pregunta: hasta qué punto son fiables los relatos históricos, una vez demostrado que en su mayoría han sido soportados y reforzados por imágenes cuya veracidad es cuestionable? (CASTELLOTE [ed.], 2003, p.262) 
Una de las características de nuestro tiempo, es que vivimos en un imaginario generalizado. La fotografía ha colaborado para la creación de imágenes impactantes y atractivas, aún más verídicas que la realidad misma. Una 'Sociedad del espectáculo', cómo lo describiría Guy Debord (1995), en el que la representación y la apariencia son más vívidas que la realidad.

Lo que caracteriza a las sociedades contemporáneas avanzadas de hoy en día, es que esas sociedades consumen imágenes y no creencias. Son por tanto -en comparación con las sociedades modernas- más liberales, menos fanáticas, aunque también más falsas y menos auténticas. (BARTHES, 1999)

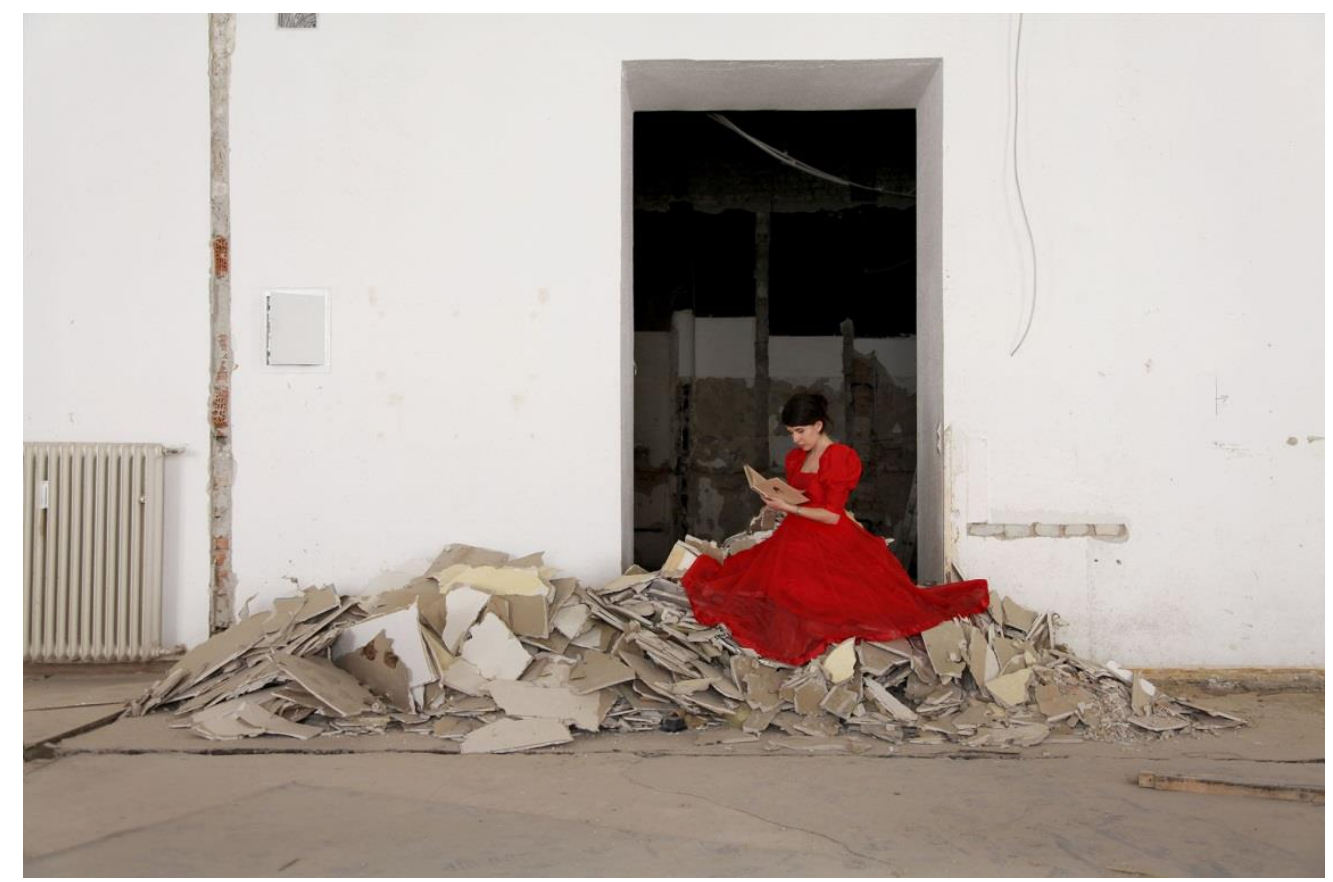

Figura 2- Laura Ribero Rueda, de la serie Transitory Places - Cinemas Metrokino, c-print, 2013. Fuente: Archivo particular. ${ }^{5}$

Mi propio proceso fotográfico se instala entre los límites de lo real y lo ficcional. En 2013 realicé un proyecto de foto-performances en salas de cine, titulado 'Transitory Places' (Figura 2). En este caso, el lugar escogido, fue el edificio que alberga la sala de cine Metrokino, una antiguo cine del siglo XIX que queda en el centro de la ciudad de Viena, en Austria.

\footnotetext{
${ }^{5}$ Para más información, dirigirse a: http://www.laribero.com
} 
Son nueve retratos en los que yo misma soy la protagonista de una historia aparente: es la documentación de un lugar en ruinas, casi destruido, monocromático, en el que entra en escena una mujer que viste ropas suntuosas y teatrales, causando un quiebre en la percepción del lugar. Esta serie se presenta como una narrativa, que trata de tránsitos, de ausencias y de presencias: el espacio escogido es una sala de cine deshabitada donde no pasa absolutamente nada, durante el tiempo que se encuentra cerrada al público.

Desde nuestro presente, asistimos a una superproducción de paisajes urbanos caracterizados por la ausencia y la soledad. No-lugares acorde a la definición de Marc Augé (2000), los cuales definen un paisaje urbano marcado por la soledad y alienación de nuestra contemporaneidad. La mujer de las fotografías, habita esos espacios asignándoles una nueva identidad, que aunque sea imaginaria, imprevisible, o improbable, hace que la mirada sobre eses lugares se transforme, sin embargo la identidad de ella misma es completamente diluida en este juego de poses, artificios y apariencias.

El término simulacro sería el que mejor sintetiza este juego entre ficción y realidad, ya que contiene en sí mismo la multiplicidad y la apariencia implícita en la percepción de lo real. Según el propio Baudrillard (2006), 'la fotografía exorciza al mundo a través de la ficción instantánea de su representación (no por su representación directa; la representación es siempre un juego con la realidad).'

Es precisamente en el arte contemporáneo, donde se abren nuevas perspectivas, nuevas lecturas e hipótesis de hechos determinados como únicos y reales. La posmodernidad es el escenario que posibilita el encuentro de la experiencia personal con la llamada memoria colectiva, aunque los puntos de referencia, tal como afirma Marc Augé (2000), hacen de la identidad del sujeto un ente fluctuante, plural y dinámico; que necesita no sólo de la apariencia sino de una producción individual de sentido.

Muestra una visión de la realidad centrada en lo impreciso y aborda desde inspiradoras perspectivas como la del simulacro, la ficción o la imaginación. Se trata de ese heideggeriano 'espacio del entre'. (...) utilizando, sin embargo, una estética altamente documental y narrativa. Se trata de hacer que esa realidad emerja como una construcción, una ficción: se intenta ficcionalizarla acentuando la mirada de lo natural mientras se introduce una visión crítica. (GONZALO PRIETO, 2003, p.72-73) 


\subsection{Imaginarios en la construcción del retrato}

La fotografía posee la capacidad de evocar la experiencia histórica (VAN DER STOK, F.; GIERSTBERG, F. \& BOOL, F. [eds.], 2008), y precisamente de ésta virtud se valen diversos artistas contemporáneos, para generar otro tipo de relatos que tienen que ver con lo personal o lo colectivo.

Cada vez que somos fotografiados, espontáneamente tomamos una posición mental en la lente del fotógrafo, justo como si su lente tomara posición sobre nosotros. Aún el más salvaje de los aborígenes en una aldea, ha aprendido cómo responder de manera espontánea en una pose frente a la cámara. Todos saben cómo adoptar una pose en un vasto campo de reconciliación imaginaria. (BAUDRILLARD, 2006)

El arte contemporáneo posee las herramientas para romper las construcciones e imaginarios, tanto discursivos como visuales, y que operan desde dos direcciones: como estereotipamos a los otros y a su vez, como los otros han creído en ese estereotipo.

Artistas como Yinka Shonibare o Shigeyuki Kihara, trabajan con la subversión de la memoria histórica y el desmantelamiento de ciertos imaginarios. La obra 'Fa'afafine: in a manner of a women', 2005 (Figura 3), de la samoana Shigeyuki Kihara ${ }^{6}$ se inscribe dentro de estos cuestionamientos.

Tres de las fotografías de ésta serie, son casi idénticas entre sí, en ellas aparece la propia artista, recostada sobre un sofá tapizado, en una clara referencia a las fotografías supuestamente documentales de la época colonial. Sin embargo, Kihara pone en tela de juicio los conceptos de exotismo y sensualidad asociados a la cultura samoana, al tratar de evidenciar su propia sexualidad: en la primera imagen, nos muestra a una samoana con el torso desnudo y una falda típica polinesia. En la segunda nos muestra la misma mujer totalmente desnuda y en la última imagen vemos la misma persona, con rasgos físicos idénticos, a excepción de la evidencia de su sexo masculino.

\footnotetext{
${ }^{6}$ Shigeyuki Kihara nació en 1975 en Samoa, Polinesia. Actualmente vive y trabaja entre Samoa, Nueva Zelanda y Australia. Para más información, dirigirse a: http://shigeyukikihara.wordpress.com
} 


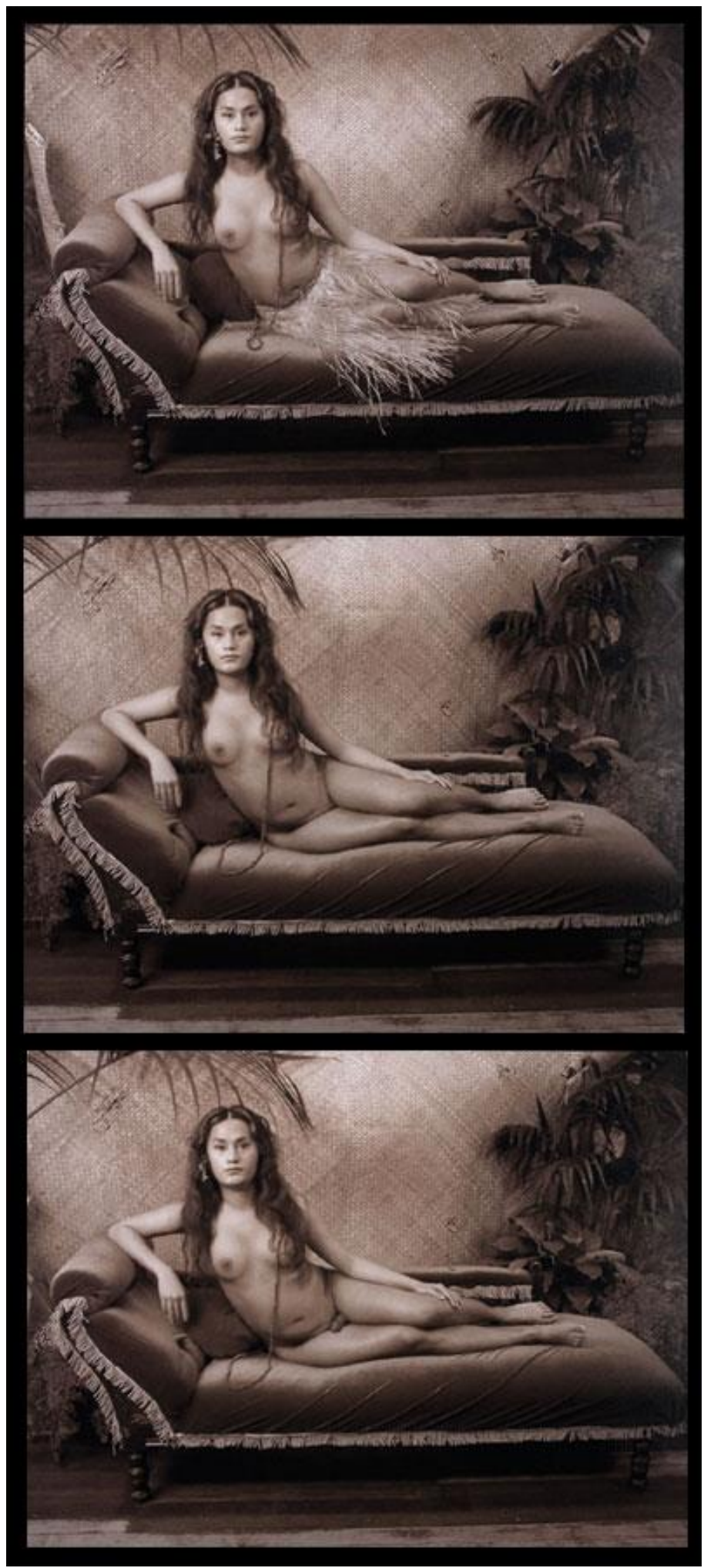

Figura 3 - Shigeyuki Kihara, de la serie Fa'a fafine: In a Manner of a Woman, c-print, 80 x $60 \mathrm{~cm}$ cada imagen, 2010. Fuente: Cortesia de Shigeyuki Kihara Studio y Milford Galleries Dunedin, Nueva Zelandia.

Kihara evidencia la sexualidad, no solo de ella sino la de su comunidad, en la que no solo existe el género masculino y el femenino, sino también el tercer sexo, el de fa'a fafine. Que dentro de la cultura samoana, engloba la aceptación y el orgullo de ser 
tanto hombre como mujer: son hombres femeninos que han sido educados como tales. No se trata de homosexualidad ni de travestismo, se trata de un género que no es excluyente ni con lo femenino ni lo masculino. (SCHMIDT, 2001).

Kihara usa su cuerpo para desafiar los estereotipos coloniales que retrataban a la mujer polinesia en poses sensuales y sexuales, exponiendo su cuerpo como objeto de deseo y como sujetos exóticos propensos a ser observados y estudiados.

Estos trabajos artísticos contemporáneos que hacen parte de nuestra investigación, evidencian cómo desde nuestra contemporaneidad, hay un quiebre en la percepción de nociones que anteriormente se asumían como totalitarias: hay una reevaluación constante acerca de la representación identidad en el retrato fotográfico.

En sentido general la fotografía documental tiende a ser asociada con la idea de un ejercicio de apropiación que, desde el aparato fotográfico, se impone sobre la realidad fotografiada (...) se asumen como prácticas legítimas las del desdoblamiento, el enmascaramiento, el disfraz, el travestismo, el maquillaje o la pose. (...) La fotografía, y en especial, el retrato fotográfico se han especializado en crear esos espacios rituales en los que el cuerpo se reafirma y se niega simultáneamente como individualidad. (...) un impulso contestatario, un deseo de revisar ciertas estructuras jerárquicas en la historia de la representación del cuerpo y en la historia de las miradas sobre el cuerpo. (...) se percibe una resistencia ante la imposición de modelos y valores que en una sociedad de masas pretende establecer una estandarización de las ideas sobre la belleza, el erotismo y la funcionalidad de los cuerpos. (CASTELLOTE [ed.], 2003, p.51)

La parodia, la hibridación, la multiplicación, la subjetividad, la apropiación de paradigmas, están presentes como conceptos y herramientas que sirven para deconstruir la mirada unilateral de la identidad y a su vez sirve a los otros, para reinventarse a sí mismos.

La historia, así como la memoria, es por tanto manipulable y susceptible de deconstruirse, para volver a reconstruirse en determinada dirección. El pasado puede atender a situaciones históricas comunes, que un individuo puede compartir con otros que hayan hecho parte de su misma sociedad y cultura. La conciencia histórica entra en juego cuando abre la posibilidad de contextualizar determinados hechos colectivos. (GIERSTBERG, F., 2008)

El 'realismo' de la imagen fotográfica no corresponde necesariamente a una verdad histórica, apenas es el registro, la apariencia. La memoria es en realidad una fuente de ambigüedades, un archivo que no es estático sino que se mezcla con lo que 
pensamos. (KOSSOY, 2002) Un imaginario que relaciona nuestras concepciones de la vida con la ideología de la sociedad, nuestros conceptos con los estereotipos sociales; en una construcción conjunta y continua de fragmentos de historias ficticias, comunitarias y personales.

\section{Conclusiones}

- La fotografía es una construcción simbólica. Tanto los fotógrafos que trabajan en el género documental como los que desarrollan ficciones en la fotografía creativa, son constructores de imaginarios, que reflejan determinados contextos culturales y sociales.

- A través de los artistas contemporáneos que hemos mencionado a lo largo de éste artículo, se demuestra que desde el arte se transgreden los modelos de identidad en el retrato fotográfico, evidenciando la pose, la simulación, y en definitiva, la construcción de la identidad en el retrato fotográfico, visando el dinamismo y la pluralidad del yo.

- Las nociones totalitarias son cada vez más imprecisas: realidad y ficción, objetividad y subjetividad, documento e imaginario, son conceptos que se entrecruzan continuamente en el lenguaje fotográfico. Los creadores trabajan en los límites de los géneros, a menudo transgrediendo el modelo utilizado, invitando a redefinir nuevos espacios de conceptualización. Lo real y lo ficticio se fusionan en la fotografía, y por tanto no existe una realidad, sino múltiples realidades que se constituyen a partir de lo simbólico.

\section{Referencias}

AUGÉ, M.; Los no lugares. Espacios de anonimato. Una antropología de la sobremodernidad. (M. Mizraji, Trad.) Barcelona: Gedisa, 2000

BARTHES, R. La cámara lúcida. Nota sobre la fotografía. (J. Sala-Sanahuja, Trad.) Barcelona: Paidós, 1999 
BAUDRILLARD, J.; Cultura y simulacro. A la sombra de las mayorías silenciosas. El efecto Beaubourg. La precesión de los simulacros. El fin de lo social. (A. Vicens, \& P. Rovira, Trads.) Barcelona: Kairós S.A, 2008.

BAUDRILLARD, J. 'Fotografía, o la escritura de la luz'. Archivo U-ABC TEORIA. Universidad Autónoma de Baja California (Tijuana-Mexicali), 14 de Enero de 2006: http://tijuanaartes.blogspot.com.es/2006/01/fotografia-o-la-escritura-de-la-luz.html Acceso: 18 mayo 2015. BORGES, J.; 'Manifiesto del Ultra. Mallorca, 1921'. En BORGES, J. et al. Textos recobrados, 1919-1929. Madrid: Emecé España, 1997, p.86.

BOUTROS, N.; 'Nabil Boutros: Egyptians'. Nafas Art Magazine, Marzo de 2011: http://universes-in-universe.org/eng/nafas/articles/2011/nabil boutros Acceso: 14 de Mayo de 2015.

BROWN, E.; 'En/Con el mundo: Yo, ella y lo todavía no conocido', In: NosOtros. Identidad y alteridad. PhotoEspaña2003. (A. del Río Herrmann, \& M. García Lozano, Trads.) Madrid: La Fábrica Editorial, 2004.

BRAVO, L.; Ficciones Certificadas. Invención y apariencia en la creación fotográfica [19752000]. Madrid: Editorial Metáforas del Movimiento Moderno, 2006.

BUSTAMANTE, A.; Los pliegues del sujeto. Una lectura de Fernando Pessoa. Madrid: Biblioteca Nueva, 2010.

CASTELLOTE, A. [ed.]; Mapas Abiertos. Fotografía Latinoamericana 1991-2002. Barcelona: Lunwerg Editores, 2003.

CASTILLA DEL PINO, C.; Teoría de los sentimientos. Barcelona: Tusquets Editores, 2000.

DEBORD, G.; La sociedad del espectáculo. (F. Alegre y B. Rodríguez, Trad.) Buenos Aires: La Marca Editora, 1995.

DE DIEGO, E.; No soy yo. Autobiografía, performance y los nuevos espectadores. Madrid: Siruela, 2011.

GIERSTBERG, F.; 'The big History Quiz'. In: VAN DER STOK, F.; GIERSTBERG, F. \& BOOL, F. [eds.]; Questioning History. Imagining the Past in Contemporary Art. Reflect \# 7. Rotterdam, Holland: NAi Publishers; Nederlands Fotomuseum, 2008.

GILI, M. [curadora] et al.; Cartógrafos y aventureros: narradores de historias. Catálogo de Exposición. (Glossolàlia, Trad.) Barcelona: Fundación 'La Caixa', 1998.

GONZALO PRIETO, P.; Zombis, castrados, mantis y deformes: notas para una exploración de la Postfotografía. Murcia: Asociación murciana de críticos de arte, 2003.

GUASCH, A. M.; 'Una historial cultural de la posmodernidad y del poscolonialismo. Lo intercultural entre lo global y lo local'. Artes. La revista, Vol.5 (No.9), 2005, p.3-14. 
KERTÉSZ, I.; 'Yo, otro'. Quaderns Crema: Crónica del cambio, 2010, p.13.

KOSSOY, B; Realidades e Ficções na Trama Fotográfica. São Paulo, Brasil: Ateliê Editorial, 2002. PARDO SAINZ, R.; La Autorreferencialidad en el arte (1970-2011). El papel fotográfico, el vídeo y el cine doméstico como huella mnemónica en la construcción identitaria. (Tesis doctoral), Barcelona: Facultad de Bellas Artes. Universidad de Barcelona, 2011.

REBOLLAR, M.; 'El fotógrafo como fingidor. Entrevista a Joan Fontcuberta'. Revista Lápiz (No.192), 2003, p.61.

RIMBAUD, A; Cartas del vidente. (13 de Mayo de 1871). Scribd: http://es.scribd.com/doc/33377239/Cartas-Del-Vidente Acceso: 18 mayo 2015.

RUBIO, O.; 'NosOtros. Identidad y Alteridad'. In: NosOtros. Identidad y alteridad. PhotoEspaña2003. (A. del Río Herrmann, \& M. García Lozano, Trads.) Madrid: La Fábrica Editorial, 2004.

SCHMIDT, J; 'Redefining Fa'afafine: Western Discourses and the Construction of Transgenderism in Samoa.' Intersections: Gender, History and Culture in the Asian Context, Agosto de 2001: http://intersections.anu.edu.au/issue6/schmidt.html Acceso: 18 mayo 2015. TROUILLOT, M.R.; Global Transformations. Anthropology and the Modern World. New York, USA: Palgrave Macmillan, 2003.

VAN DER STOK, F.; GIERSTBERG, F. \& BOOL, F. [eds.]; Questioning History. Imagining the Past in Contemporary Art. Reflect \# 7. Rotterdam, Holland: NAi Publishers; Nederlands Fotomuseum, 2008. 